\title{
Spectrum of Congenital Heart Diseases in Eastern Nepal: A tertiary care hospital experience
}

\author{
Prashant Shah $^{1}$, Kunjang Sherpa ${ }^{2}$, Naveen Kumar Pandey ${ }^{1}$, Bhawani Manandhar ${ }^{1}$, Sahadeb Prasad \\ Dhungana ${ }^{1}$ \\ ${ }^{1}$ Division of Cardiology, Department of Internal Medicine ${ }^{2}$ Department of Internal Medicine, B.P. Koirala \\ Institute of Health Sciences, Dharan, Nepal
}

\author{
Correspondence \\ Dr Prashant Shah \\ Department of Cardiology, B.P. \\ Koirala Institute of Health \\ Sciences, Dharan, Nepal \\ Email: \\ prashant0063@hotmail.com
}

DOI: http://dx.doi.org/10.3126/ jemsn.v12i4.15593

Article received: Sept $1^{\text {st }} 2016$ Article accepted: $23^{\text {rd }}$ Dec 2016

\begin{abstract}
Background \& Objectives: Congenital heart diseases are neglected especially in world's poorest nations and appear to be ignored and unexplored dimension of health. The exact prevalence and spectrum of congenital heart diseases in Nepal is largely unknown. The aim of this study was to describe the local experience on the magnitude and the pattern of congenital heart disease in order to increase the awareness of the public and health policy makers on its burden in Nepal. Materials \& Methods: This is an observational hospital based study carried out in a tertiary care hospital in Eastern Nepal. The duration of this study was from April 2015 to July 2016. The echocardiography reports of all patients clinically suspected of having congenital heart disease were retrieved, and their diagnostic details were extracted. Only patients of day one of life to 14 years of age were included. Congenital heart diseases like bicuspid aortic valve, mitral valve prolapse and various inherited cardiomyopathies were excluded. Results: A total of 330 echocardiograms were performed for clinically suspected congenital heart disease. The mean age of study population was $22.31 \pm 34.08$ months with male to female ratio of $1.2: 1$. $23 \%$ of clinically suspected congenital heart disease cases turned out to have normal echocardiography. Acyanotic congenital heart disease was most common $(81.5 \%)$ followed by cyanotic congenital heart disease $(14.2 \%)$ and obstructive congenital heart disease (4.3\%). Atrial septal defect was found to be the most common form of acyanotic congenital heart disease $(52 \%)$ which was followed by ventricular septal defect $(28.8 \%)$ and patent ductus arteriosus $(14.8 \%)$. Tetralogy of Fallot and double outlet right ventricle were the most common form of cyanotic CHD representing $44.4 \%$ of all cyanotic patients. Pulmonary stenosis was the most common obstructive congenital heart disease observed in this study population $(63.6 \%)$. Rarer entities, like d-transposition of great arteries, congenitally corrected transposition of great arteries, various types of total anomalous pulmonary venous drainage, double inlet left ventricle, interrupted aortic arch, Shone complex, etc. were also observed, however represented only the minority of the study population. Conclusion: The spectrum of congenital heart disease seen in this study very likely and only represents the tip of the iceberg. Public awareness programmes and training of health care personnel needs to be emphasized in order to facilitate its early diagnosis and improve its outcome.

Key words: Congenital heart diseases; paediatric cardiology; paediatric echocardiography
\end{abstract}

Citation: Shah P, Sherpa K, Pandey NK, Manandhar B, Dhungana SP. Spectrum of Congenital Heart Diseases in Eastern Nepal: A tertiary care hospital experience. JCMS Nepal. 2016;12(4):137-42.

\section{INTRODUCTION}

The 20th century observed a major revolution in health as majority of infectious diseases got eradicated from the developed nations and were replaced by chronic non-infectious illnesses like hypertension and diabetes. Due to this epidemiological transition, chronic medical illnesses started getting more emphasis in medical 
research, health care programmes and public awareness programmes. However, this transition was devastating for the developing nations where a new burden of chronic illnesses and HIV/ AIDS were added to the prevailing problems of malnutrition and infectious diseases like tuberculosis, malaria, diarrhoea, etc. leading to double burdening of the developing nations. ${ }^{1}$ This further crippled the poorly funded and poorly managed health care system of the developing nations.

Congenital heart diseases (CHD) are major public health problem worldwide accounting for about one -third of all major congenital abnormalities. ${ }^{2}$ Furthermore, CHD are chronic illnesses because their adverse effects get manifested mostly in adulthood and result in significant disability, morbidity and mortality. Hence early detection and timely management is important for CHD. However, CHD are neglected world-wide and especially in world's poorest nations where hunger, malnutrition and infectious diseases still dominate the burden of illnesses. CHDs persist to be ignored and unexplored dimension of health. They remain largely unattended by the modern revolutionary medical researches and are yet to appear anywhere on the priority list of health care system. The reasons for inattention towards CHD could be-1) More attention towards the more publicized chronic medical illnesses of affluence like coronary artery disease; 2) General perception that CHD are either untreatable or have poor outcome despite costly treatment; 3) The shortage of data on the burden of CHD caused by reduced local expertise and poor funding. To the best of our knowledge, it is not inappropriate to label them as orphan diseases.

The prevalence of CHD varies worldwide and depends not only on geography but also on the age of study population and whether the survey is conducted on clinical basis or with the help of echocardiography. The reported incidence of CHD is eight to $10 / 1000$ live births according to various series from different parts of the world. ${ }^{3}$ A study conducted in schools of Kathmandu reported a prevalence of one per thousand. ${ }^{4}$ The incidence of CHD was 5.8 per 1000 hospitalized patients in another study from Nepal. ${ }^{5}$ Community-based data for incidence of CHD at birth in Nepal is lacking since a large number of births in our country take place at home and hospital statistics are unlikely to be truly representative.

The aim of this study was to describe our experience on the spectrum of simple and complex CHD in paediatric age groups based on echocardiographic study after initial clinical suspicion by primary care physicians. The objective behind this brief communication is to overcome the prevailing lack of focus on CHD, and to increase the awareness of the public and health policy makers on the burden of CHD in Nepal.

\section{MATERIALS AND METHODS}

This was an observational hospital based study done in B.P. Koirala Institute of Health Sciences (BPKIHS), which is the only tertiary care centre in eastern part of Nepal having super-speciality services like cardiology and cardio-thoracic surgery. We perform about five to 15 neonatal and paediatric echocardiography per week for suspected CHD. All paediatric and adult echocardiography for suspected CHD are done following standard protocol using segmental analysis, using S5 and S8 probes of Philips IE33 Matrix echocardiography machine. Most of the patients diagnosed with CHD are medically treated and followed up periodically by paediatricians and cardiologists at our own centre. Patients needing urgent surgical intervention get referred to other centres, until recently, when we started our own paediatric cardiac interventions and paediatric and adult cardio-thoracic surgery unit.

This study was carried out from April 2015 to July 2016. We only included paediatric patients from day one of life to $14 \mathrm{yrs}$ of age with suspected CHD. We adopted the definition of CHD as proposed by Mitchel et al., ${ }^{6}$ which states that a CHD is gross structural abnormality of the heart or intra-thoracic great vessels that is actually or potentially of functional significance. Because various congenital cardiac lesions often co-exist in same patient, each individual CHD lesion were counted separately for descriptive purpose (for example if a patient had atrial septal defect co-existing with ventricular septal defect, it was described as two CHD in one patient). Patients with bicuspid aortic valve, mitral valve prolapse and inherited cardiomyopathies were excluded. The diagnostic details were extracted and entered on an Excel data-sheet. SPSS version 16 was used for statistical analysis.

\section{RESULTS}

A total of 330 echocardiography were performed for clinically suspected CHD in the specified age group during this period. The mean age of study population was $22.31 \pm 34.08$ months which 
Table 1: Gender distribution of various Congenital Heart Disease $(n=254)$

$\begin{array}{llll}\text { Cardiac lesions } & \text { Male } & \text { Female } & \text { Total } \\ \text { Acyanotic CHD } & 108(52.2 \%) & 99(47.8 \%) & 207(81.5 \%) \\ \text { Cyanotic CHD } & 19(52.8 \%) & 17(47.2 \%) & 36(14.2 \%) \\ \text { Obstructive CHD } & 6(54.5 \%) & 5(45.5 \%) & 11(4.3 \%) \\ \text { Total } & 133(52.36 \%) & 121(47.8 \%) & 254(100 \%)\end{array}$

Table 2: Gender distribution of Acyanotic Congenital Heart Diseases $(n=207$; lesions=236)

\begin{tabular}{|c|c|c|c|}
\hline \multicolumn{4}{|c|}{ Acyanotic Congenital Heart Diseases $(n=207)$} \\
\hline \multirow[t]{2}{*}{ Cardiac lesions } & \multicolumn{2}{|c|}{ Frequency } & \multirow{2}{*}{$\begin{array}{l}\text { Male: } \\
\text { Female }\end{array}$} \\
\hline & Male & Female & \\
\hline Atrial septal defect (52\%) & 64 & 58 & $1.1: 1$ \\
\hline (ASD) & & & \\
\hline Os ASD $(90.2 \%)$ & 57 & 53 & \\
\hline Op ASD $(7.4 \%)$ & 5 & 4 & \\
\hline Sv ASD $(1.6 \%)$ & 2 (+PAPVC) & 0 & \\
\hline Cs $\operatorname{ASD}(0.8 \%)$ & 0 & 1 (with unroofed CS) & \\
\hline Ventricular septal defect (28.8\%) & 37 & 31 & 1.2:1 \\
\hline (VSD) & & & \\
\hline Perimembranous VSD (47\%) & 17 (1 with GT) & 15 (2 with GT) & \\
\hline Muscular VSD (37.8\%) & 14 (1 with IVI) & 11 & \\
\hline Outlet VSD (1.5\%) & 1 & 0 & \\
\hline Inlet VSD (14.71\%) & 5 & 5 & \\
\hline Patent ductus arteriosus (14.8\%) & 18 & 17 & 1.1:1 \\
\hline
\end{tabular}

(PDA)

$\begin{array}{llll}\text { ASD with VSD } & 16 & 9 & \\ \text { ASD with PDA } & 8 & 6 & 2.5: 1 \\ \text { VSD with PDA } & 0 & 2 & \text { NA } \\ \text { Complete AVSD } & 5 & 2 & \text { NA } \\ \text { Partial AVSD } & 0 & 2 & \text { NA }\end{array}$

Abbreviations: ASD- atrial septal defect, Os ASD- Ostium secundum ASD, Op ASD- Ostium primum ASD, Sv ASD- Sinus venosus ASD, Cs ASD- Coronary sinus ASD, VSD- ventricular septal defect, GT- Gasul's transformation, PDA-patent ductus arteriosus, PAPVC-partial anomalous pulmonary venous connection, AVSD- atrio-ventricular septal defect, CS-coronary sinus, IVI -isolated ventricular inversion.

included $180(54.5 \%)$ male patients and 150 $(45.5 \%)$ female patients. Out of 330 echocardiography done for clinically suspected CHD, 76 (23\%) were normal and 254 (77\%) were diagnosed to have CHD. There was no statistically significant difference between the two genders in over-all occurrence of CHD ( $\mathrm{p}=0.503)$.

Acyanotic CHD were the most common form of CHD encountered, comprising of $81.5 \%$ of those having CHD, followed by cyanotic CHD (14.2\%) and obstructive CHD (4.3\%). There was no statistical significant difference between the two genders in terms of distribution of types of CHD $(\mathrm{p}=0.966)$ as shown in table 1 . In 207 patients found to have acyanotic CHD, 236 different cardiac lesions were identified (Table 2). Atrial septal defect (ASD) was the most common CHD, present in $52 \%$ of the patients with acyanotic CHD and $48 \%$ of all CHD patients. Ostium secundum ASD (Os-ASD) was the most common type of ASD followed by Ostium primum ASD (Op-ASD), Sinus venosus ASD (Sv-ASD) and Coronary sinus ASD (Cs-ASD) representing 90.2\%, 7.4\%, 1.6\%, and $0.8 \%$ respectively. $20 \%$ of ASD were associated 
Table 3: Gender Distribution of Cyanotic Congenital Heart Diseases ( $n=36)$

\begin{tabular}{|c|c|c|c|}
\hline \multicolumn{4}{|c|}{ Cyanotic Congenital Heart Diseases $(n=36)$} \\
\hline \multirow[t]{2}{*}{ Cardiac lesions } & \multicolumn{2}{|c|}{ Frequency } & \multirow{2}{*}{$\begin{array}{l}\text { Male: } \\
\text { Female }\end{array}$} \\
\hline & Male $(n=19)$ & Female(n=17) & \\
\hline TOF $(16.7 \%)$ & 4 & 2 & $2: 1$ \\
\hline DORV+ VSD+ Pulmonary stenosis $(22.2 \%)$ & 4 & 4 & $1: 1$ \\
\hline DORV+ VSD + Pulmonary atresia (5.6\%) & 1 & 1 & $1: 1$ \\
\hline Tricuspid atresia + VSD + PS (11.1\%) & 1 & 3 & $1: 3$ \\
\hline d-TGA $(13.9 \%)$ & 3 & 2 & $1.5: 1$ \\
\hline cc-TGA $(8.3 \%)$ & 1 & 2 & $1: 2$ \\
\hline Supracardiac TAPVC without obstruction $(8.3 \%)$ & 2 & 1 & $2: 1$ \\
\hline Supracardiac TAPVC with obstruction $(2.8 \%)$ & 0 & 1 & NA \\
\hline Mixed type TAPVC (2.8\%) & 0 & 1 & NA \\
\hline Truncus Arteriosus-type I (2.8\%) & 1 & 0 & NA \\
\hline Double inlet left ventricle with TGA with PAH (2.8\%) & 1 & 0 & NA \\
\hline $\begin{array}{l}\text { Atrio-ventricular septal defect with DORV with Malposed } \\
\text { great arteries with pulmonary artery hypertension }(2.8 \%)\end{array}$ & 1 & 0 & NA \\
\hline
\end{tabular}

Abbreviations: TOF- tetralogy of Fallot, DORV-double outlet right ventricle, VSD-ventricular septal defects, PS-pulmonary stenosis, d-TGA-d-transposition of great arteries, cc-TGA-congenitally corrected transposition of great arteries, TAPVC-total anomalous pulmonary venous connection, PAH-pulmonary arterial hypertension.

with presence of ventricular septal defects (VSD) and $11 \%$ of them were associated with presence of PDA. We diagnosed 2 cases of Sv-ASD and both were associated with partial anomalous pulmonary venous connection (PAPVC) of right upper pulmonary vein with superior vena-cava. We observed only one case of Cs-ASD which was associated with unroofed coronary sinus and presence of persistent left superior vena-cava draining directly into the left atrium.

Ventricular septal defect was the 2nd most common acyanotic CHD followed by PDA, representing $28.8 \%$ and $14.8 \%$ of acyanotic heart diseases respectively. Perimembranous VSD was the commonest type of VSD (47\%) followed by muscular VSD (36.8\%) and inlet VSD (14.7\%). Outlet VSD was seen in only one patient (1.5\%). 3 large perimembranous VSDs $(9.4 \%$ of all perimembranous VSD) were associated with acquired right ventricular outflow obstruction, which is also known as Gasul's transformation.

Nine out of 207 (4.3\%) patients diagnosed to have acyanotic CHD had atrio-ventricular septal defect (AVSD), out of whom seven (77.8\%) had complete AVSD and $2(22.2 \%)$ had partial AVSD.

The distribution of cyanotic CHD is summarized in table 3. Tetralogy of Fallot (TOF) and double outlet right ventricle (DORV) were the most common form of cyanotic CHD representing $44.4 \%$ of all cyanotic patients. d-Transposition of great arteries (d-TGA) and tricuspid atresia with VSD and pulmonary stenosis represented $13.8 \%$ and $11.1 \%$ of cyanotic CHD respectively. cc-Transposition of Great Arteries (cc-TGA) and unobstructed supracardiac TAPVC were seen in equal numbers, each representing $8.3 \%$ of patients with cyanotic CHD. Unobstructed supracardiac TAPVC, mixed type TAPVC, truncus arteriosus, DILV with TGA, AVSD with DORV with malposed great arteries were also observed, however each represented less than $5 \%$ of cyanotic CHD.

Among congenital obstructive lesions (Table 4), valvular pulmonary stenosis was most common $(63.6 \%)$ followed by branch pulmonary artery stenosis $(18.2 \%)$. We also observed a case of interrupted aortic arch and a case of Shone complex having supra-mitral ring, hypoplastic left ventricle, sub-aortic membrane, hypoplastic aortic arch and severe coarctation of aorta.

We also observed few rare and complex cardiac entities which included one double chambered right ventricle (DCRV), one left ventricular noncompaction, one isolated ventricular inversion, three cases of situs inversus with dextrocardia having normal cardiac anatomy and three persistent pulmonary hypertension in new born which we couldn't classify into the above mentioned groups.

\section{DISCUSSION}

Coronary Heart Disease carries significant morbidity and mortality, however often gets ignored. Public unawareness, limited availability of 
paediatric cardiologists, skilled paediatric echocardiologists, paediatric intervention cardiologists and paediatric cardio-thoracic surgeons appear to be common reasons due to which CHD get less medical attention. The diagnosis of CHD often get delayed and appropriate treatment is either never instituted or get delayed unduly. This study highlights the burden and the spectrum of various congenital heart diseases from a single tertiary care centre, and is likely to represent only the tip of the iceberg.

As per previous reports, there are regional differences in the prevalence and distribution of CHDs. The reported prevalence at birth ranges from six to 13 per thousand live birth. ${ }^{7}$ The reported incidence of CHD in different parts of Nepal varies from 1.3 to 5.8 per thousand live births. ${ }^{5,8}$ In infants with critical $\mathrm{CHD}$, the risk of mortality and morbidity increases with delay in diagnosis and timely referral to centre with expertise play crucial role in their outcome. ${ }^{9}$ This study was conducted with the aim of increasing awareness about CHD among general population as well as health care personnel.

Our study revealed ASD as the most common CHD, present in $52 \%$ of patients with acyanotic CHD and $48 \%$ of all CHD patients. Worldwide, ASD is the most common form of CHD accounting for up to $13 \%$ of CHD and having a prevalence of 1.64 per 1000 live births. ${ }^{2}$ It can be found in isolation or in association with other congenital cardiac anomalies. The size, location and functional consequences of ASD are variable. It may remain undiagnosed until adult life due to long asymptomatic period. The occurrence of ASD was much higher in our study population $(52 \%)$ and out of all ASDs, $90 \%$ were Os-ASD. We attribute this discrepant four fold higher prevalence of ASD to lower age group of our study population.

VSD is the most common CHD at birth, however accounts for only $10 \%$ of CHD in adults due of high rates of spontaneous closure. ${ }^{10}$ VSD was 2nd most common form of CHD in our study accounting for up to $29 \%$ of total CHD. We attribute this higher prevalence again to the lower age of our study population. Our study revealed the predominance of peri-membranous defects $(47 \%)$ followed by muscular VSD (38\%). Outlet VSD was least common among all cases of VSD. Interestingly, three of our large VSD patients (4.4\%) demonstrated acquired right ventricular outflow obstruction, which is also known as
Gasul's transformation.

PDA was the third most common form of CHD in our study population. The clinical features of PDA are determined by degree of left to right shunting and difference between pulmonary and systemic vascular resistance. In most of the studies, there is a female predominance in the occurrence of PDA and greater incidence among those born at high altitude. ${ }^{2,11}$ Our study did not show much difference in the occurrence of PDA between the two genders. Cyanotic lesions comprise around one third of potentially fatal forms of CHD. ${ }^{12}$ Early recognition and stabilization is critically important for favourable outcome of new-borns with these lesions. We observed $14.2 \%$ occurrence of cyanotic CHD in our study population, which is lower than previous reports. One of its reasons could be early clinical detection of cyanotic CHD leading to anxiety among parents and treating physicians and early referral to established cardiac centres. Cyanotic CHD having TOF physiology (i.e. classical TOF, DORV with VSD and PS, DORV with VSD and pulmonary atresia, tricuspid atresia with VSD and PS) were the predominant diagnosis accounting for $56 \%$ of our cyanotic patients. DORV with VSD with PS was commoner that the classical TOF in our study. d-TGA was more common than cc-TGA. We also observed five cases of TAPVC, out of which four were supracardiac TAPVC and one was of mixed type. Out of patients with TAPVC, only one was obstructed (20\%). Rarer complex entities, like truncus arteriosus, double inlet left ventricle with TGA, atrio-ventricular septal defect with DORV were also observed which accounted for less than $10 \%$ of cyanotic CHD.

Stenosis of pulmonary valve is relatively common congenital obstructive cardiac defect carrying benign clinical course and slight female predominance. ${ }^{13}$ Pulmonary stenosis was the most common obstructive congenital cardiac defect in our study also. We also witnessed female preponderance with male: female ratio being 2:5. One male new born was diagnosed as having interrupted aortic arch and another male new born was diagnosed as having Shone complex. Both of them refused treatment and lost to follow up.

Other rarer unclassified congenital CHD included situs inversus with dextrocardia, isolated ventricular inversion, left ventricular non-compaction, double chambered right ventricle were also observed in this study but each accounted for less than $5 \%$ of the observed CHD. 


\section{CONCLUSION}

CHD are not uncommon, however their diagnosis is often missed. Delay in diagnosis and initiation of appropriate therapy often carry devastating consequences for most of the CHD. The striking features of cyanotic CHD and complex CHD make them more clinically evident, however mostly carry guarded prognosis even after early detection. The acyanotic CHD are clinically more deceptive and their diagnosis can easily be missed. Delay in diagnosis or institution of appropriate therapy often leave them vulnerable to infections and pulmonary hypertension. The spectrum of CHD seen in this study very likely represents the tip of the iceberg.

\section{RECOMMENDATIONS}

Public awareness programmes and training of health care personnel for early detection of CHD needs to be prioritized to improve the outcome of CHD. We recommend the health policy makers to promote programmes for early detection and referral of CHD patients. We also need a national protocol for timely management of CHD, to prevent its long term adverse effect on morbidity, mortality and disability. Improving public awareness regarding CHD (via advertisement on national television channels for example) can be the most cost-effective initial strategy.

\section{ACKNOWLEDGEMENT}

We acknowledge our paediatrics team for keeping high degree of suspicion for CHD and referring their patients for evaluation and management of CHD. This study would have been impossible without their contribution. We also acknowledge $\mathrm{Dr}$ Ojaswee Sherpa for proofreading the final version of this manuscript for publication.

\section{REFERENCES}

1. Marshall SJ. Developing countries face double burden of disease. Bull World Health Organ. 2004 Jul;82(7):556. PMID:15500291.

2. Van der Linde D, Konings EE, Slager MA, Witsenburg M, Helbing WA, Takkenberg JJ, et al. Birth prevalence of congenital heart disease worldwide: a systemic review and metaanalysis. J Am Coll Cardiol. 2011;58:2241. DOI: 10.1016/j.jacc.2011.08.025. PMID:22078432.

3. Fyler DC, Buckley LP, Hellenbrand WE, Cohn HE, Kirklin JW, Nadas AS, et al. Report of he New England Regional Infant Care Program. Pediatrics 1980;65 Suppl: 375-461.

4. Prajapati D, Sharma D, Regmi PR, Khanal H, Baidya SG, Rajbhandari S, et al. Epidemiological survey of Rheumatic fever, Rheumatic heart disease and Congenital heart diseaseamong school children in Kathmandu valley of
Nepal. Nepalese Heart Journal 2013;10(1):1-5.

5. Shah GS, Singh MK, Pandey TR, Kalakheti BK, Bhandari GP. Incidence of congenital heart disease in tertiary care hospital. KUMJ. 2008;21:33-6.

6. Mitchell SC, Korones SB, Berendes HW. Congenital heart disease in 56,109 Birth Incidence and Natural History. Circulation 1971 March 1;43:323-32. DOI: 10.1161/01.CIR.43.3.323. PMID:5102136.

7. Khoshnood B, Lelong N, Huyel L, Thieulin AC, Jouannic $\mathrm{JM}$, Magnier S, et al. Prevalence, timing of diagnosis and mortality of newborns with congenital heart defects: a population based study. Heart 2012;98:1667. DOI: 10.1136/heartjnl-2012-302543. PMID:22888161.

8. Bahadur KDM, Sharma D, Shrestha MP, Gurung S, Rajbhandari S, Malla R, et al. Prevalence of rheumatic and congenital heart disease in school children of Kathmandu valley in Nepal. Indian Heart J 2003;55:615-18. PMID:14989511.

9. Kuehl KS, Loffredo CA, Ferencz C. Failure to diagnose congenital heart disease in infancy. Pediatrics 1999;103:743. DOI: $\quad$ 10.1542/peds.103.4.743. PMID: 10103296

10. Du ZD, Roguin N, Wu XJ. Spontaneous closure of muscular ventricular septal defect identified by echocardiography in neonates. Cardiol Young. 1998;8:500. DOI: $\quad 10.1017 / \mathrm{S} 1047951100007174$. PMID:9855105.

11. Record RG, McKeown T. Observations relating to the etiology of patent ductus arteriosus. Br Heart J. 1953; 15:376. DOI: $10.1136 / \mathrm{hrt} .15 .4 .376$.

12. CN Talner. Report of the New England Regional infant Cardiac program. Pediatrics. 1980;65:375.

13. Campbell M. Factors in the etiology of pulmonary stenosis. $\mathrm{Br}$ Heart J. 1962;24:625. DOI: 10.1136/ hrt.24.5.625. PMID:14018144. 